\title{
Ferimento em tórax com arma branca oculta na lesão: relato de caso
}

\author{
Chest wound with a melee weapon concealed in the injury: case report
}

Lesión en el pecho con una puñalada oculta en la lesión: reporte de caso

Marcos André Filgueiras Dias ${ }^{1 *}$, Frank Pinheiro Pessoa Coelho de Macedo ${ }^{1}$, Marcel de Aguiar Raposo da Câmara Coelho', Gabriel Reis Di Tommaso ${ }^{1}$, Juan Eduardo Rios Rodriguez ${ }^{3}$, Dâmmarys Venância Freire Nascimento ${ }^{3}$, Maria Carolina Coutinho Xavier Soares².

\section{RESUMO}

Objetivo: Relatar um caso de ferimento por arma branca em tórax, com presença de corpo estranho oculto. Relato do caso: Paciente adulto e jovem, com trauma torácico penetrante, transferido do interior do estado e recebido, cerca de seis horas depois, em hospital da capital, com ferimento por arma branca no tórax posterior. Reportou dor torácica, apresentava vias aéreas pérvias, ventilação e oxigenação preservadas, hemodinamicamente estável, escore de coma de Glasgow de 15 e ferimentos no dorso. Radiografia mostrava objeto metálico inserido no tórax. A tomografia computadorizada evidenciou um objeto metálico transfixando parede torácica posterior com lesão pulmonar. Indicada toracotomia exploradora para abordagem adequada, obteve-se tratamento definitivo com sucesso. Considerações finais: Os ferimentos por arma branca no tórax são relativamente comuns. Acometem, principalmente, homens jovens e têm associação com a violência. Para o diagnóstico das lesões, as tomografias computadorizadas são acuradas. É necessário ter um diagnóstico conciso, garantindo a ventilação antes de qualquer intervenção definitiva.

Palavras-chave: Cirurgia geral, Ferimentos e lesões, Tomografia, Traumatismos torácicos.

\section{ABSTRACT}

Objective: To report a case of melee weapon wound in the chest, with the presence of a foreign body concealed. Case report: Young adult patient, with penetrating chest trauma, transferred from the interior of the state and received, approximately six hours later, in hospital in the capital, with a melee weapon wound in the posterior chest. He reported chest pain, had patent airways, preserved ventilation and oxygenation, hemodynamically stable, Glasgow coma score of 15, torso injuries. Radiography showed a metallic object inserted in the chest. Computed tomography showed a metallic object transfixing the posterior chest wall with lung injury. Indicated exploratory thoracotomy for appropriate approach, we obtained definitive treatment successfully. Final considerations: chest melee weapon wounds are relatively common. They mainly affect young men and are associated with violence. For the diagnosis of lesions, the computed tomography are accurate. It is necessary to have a concise diagnosis, ensuring ventilation before any definitive intervention.

Key words: General surgery, Wounds and injuries, Tomography, Thoracic injuries.

\section{RESUMEN}

Objetivo: Reportar un caso de herida por arma blanca en el pecho, con retención de un cuerpo extraño dentro de la lesión. Informe del caso: Paciente adulto joven, con traumatismo torácico penetrante, transferido desde el interior del estado y recibido, aproximadamente seis horas después, en un hospital de la capital, con una

\footnotetext{
${ }^{1}$ Hospital Universitário Getúlio Vargas (HUGV), Manaus - AM. *E-mail: medkinho@gmail.com

2 Instituto de Cirurgia do Estado do Amazonas (ICEA), Manaus - AM.

3 Universidade Federal do Amazonas (UFAM), Manaus - AM.
} 
herida de arma blanca en el tórax posterior. Informó dolor en el pecho, tenía vías respiratorias patentes, ventilación y oxigenación preservadas, hemodinámicamente estable, puntaje de coma de Glasgow de 15, lesiones en la espalda. La radiografía mostró un objeto metálico insertado en el cofre. La tomografía computarizada mostró un objeto metálico transfixiando la pared torácica posterior con lesión pulmonar. Indicada toracotomía exploratoria de enfoque apropiado, obtuvimos un tratamiento definitivo con éxito. Consideraciones finales: Las heridas por arma blanca en el pecho son relativamente comunes. Afectan principalmente a hombres jóvenes y que están asociados con la violencia. Para el diagnóstico de lesiones, las tomografías computarizadas son precisas. Es necesario tener un diagnóstico conciso, asegurando la ventilación antes de cualquier intervención definitiva.

Palabras clave: Cirugía General, Heridas y traumatismos, Tomografía, Traumatismos torácicos.

\section{INTRODUÇÃO}

O trauma, por sua alta prevalência no mundo, passou a ser considerado um problema de saúde pública associado à alta morbimortalidade, tanto em países desenvolvidos como em desenvolvimento. Segundo a Organização Mundial de Saúde (OMS), morrem mais de nove pessoas por minuto vítimas de trauma (ZANETTE GZ, et al., 2019). Na atualidade, o trauma é a principal causa de morte nas primeiras quatro décadas de vida (DA SILVA LAP, et al., 2017). O trauma torácico representa de $10 \%$ a $15 \%$ do total de traumas no mundo. No Brasil, essa taxa corresponde a 7,3\% das ocorrências (ZANETTE GZ, et al., 2019).

Os traumas torácicos podem ser classificados em contundentes ou penetrantes. Entre os traumas penetrantes, as lesões no dorso do tórax são geralmente decorrentes de punhaladas, inserção de objetos penetrantes e lesões por armas de fogo (ILHAN M, et al., 2016).

Os ferimentos por arma branca no tórax são uma forma de injúria penetrante relativamente comum. Embora a incidência de facadas varie em diferentes países, a ocorrência desse tipo de trauma é significativa nas situações de violência (LAISAAR T, 2005; APILIOGULLARI B, et al., 2014; JOHANNESDOTTIR U, et al., 2019; NUMMELA MT, et al., 2019).

A área mais vulnerável às armas brancas é o tórax anterior, pois o dorso é composto de densa musculatura e escápulas. Porém, apesar desse dado anatômico, é preciso atentar ao fato de que apenas examinar a ferida externa pode ser enganoso (FULLUM TM, et al., 1990; ZEBELE C, et al., 2011). Nesse contexto, os ferimentos por arma branca no tórax podem comprometer órgãos internos, causando hemorragias, choque, infecções e até morte, sendo determinantes críticos de admissões em unidades de emergência e de óbitos por trauma (APILIOGULLARI B, et al., 2014; JOHANNESDOTTIR U, et al., 2019).

Entre os traumas penetrantes por arma branca, é baixa a ocorrência dos casos em que há a retenção do corpo estranho perfurante (CEP) na lesão. Apesar dessa baixa frequência, eles merecem extrema atenção, pois a permanência do CEP pode passar despercebida, mesmo com o mais minucioso dos atendimentos.

A retenção do CEP é altamente suscetível à contaminação bacteriana, podendo provocar maior resistência aos antimicrobianos, além do risco de lesões internas e migração (APILIOGULLARI B, et al., 2014). Diante disso, o manejo adequado e rigoroso dos acometidos é imperativo. Ferramentas de avaliação, como o próprio exame físico, a radiografia, a ultrassonografia e a tomografia computadorizada (TC), ajudam a identificar as injúrias associadas (APILIOGULLARI B, et al., 2014; JOHANNESDOTTIR U, et al., 2019).

Como o diagnóstico desses traumas necessita tanto da propedêutica clínica quanto da propedêutica armada com métodos de imagem, realizar um exame físico rigoroso não afasta a necessidade do uso da TC, por sua relevância na avaliação das lesões de trajeto adicionais (LTA) e na visualização dos CEP que possam estar retidos e ocultos.

Este relato tem por objetivo enfatizar que proporcionar conforto respiratório ao paciente, evitar explorar o ferimento torácico ou manipular o CEP, visível ou oculto, aliado ao diagnóstico das possíveis LTA com auxílio da TC, pode reduzir a possibilidade de sequelas ao doente.

REAS/EJCH | Vol.Sup.n.45 | e3221 | DOI: https://doi.org/10.25248/reas.e3221.2020 Página 2 de 8 


\section{DETALHAMENTO DO CASO}

Adulto jovem, masculino, 23 anos, natural e procedente de um município da região metropolitana da capital Manaus, no estado do Amazonas, previamente hígido, queixando agressão física com uso de arma branca (pequena faca), em localidade rural deste município, em junho de 2019.

O paciente recebeu o primeiro atendimento no hospital local da sua cidade e, com sinais vitais estáveis, foi referenciado para avaliação cirúrgica na capital do estado, sendo recebido, após cerca de seis horas do ocorrido, no setor de politrauma de um hospital de urgências, admitido pela equipe de cirurgia geral.

À admissão, relatou apenas dor moderada em base posterior do hemitórax esquerdo, informando ingestão prévia de bebida alcoólica, negando dispneia, alergias, uso de ilícitos, outras comorbidades e demais queixas. Apresentava-se eutrófico, contactante, mantendo sinais vitais estáveis, pressão arterial de 145 por 100 milímetros de mercúrio $(\mathrm{mmHg})$, frequência cardíaca de 105 batimentos por minuto, oximetria de pulso de $98 \%$ ao ar ambiente, sem critérios de instabilidade. Realizada a avaliação focada com ultrassonografia no trauma (FAST), que foi negativa.

Durante avaliação cirúrgica: vias aéreas pérvias, sem cervicalgia; murmúrio vesicular sem modificação importante no hemitórax esquerdo e sem ruídos adventícios; normocorado, pulsos e perfusão periféricos preservados, ritmo cardíaco regular; abdome plano, com ruídos hidroaéreos normais, flácido e indolor à palpação; pupilas fotorreagentes e isocóricas, escore de coma de Glasgow de 15; ferimento suturado no dorso torácico, medindo cerca de $3 \mathrm{~cm}$, na região paravertebral inferior do hemitórax esquerdo, com discreto hematoma local, além de ferimentos superficiais associados, sem a visualização do CEP (Figura 1).

Figura 1 - Paciente posicionado na mesa cirúrgica com exposição dos ferimentos no dorso, descritos acima.

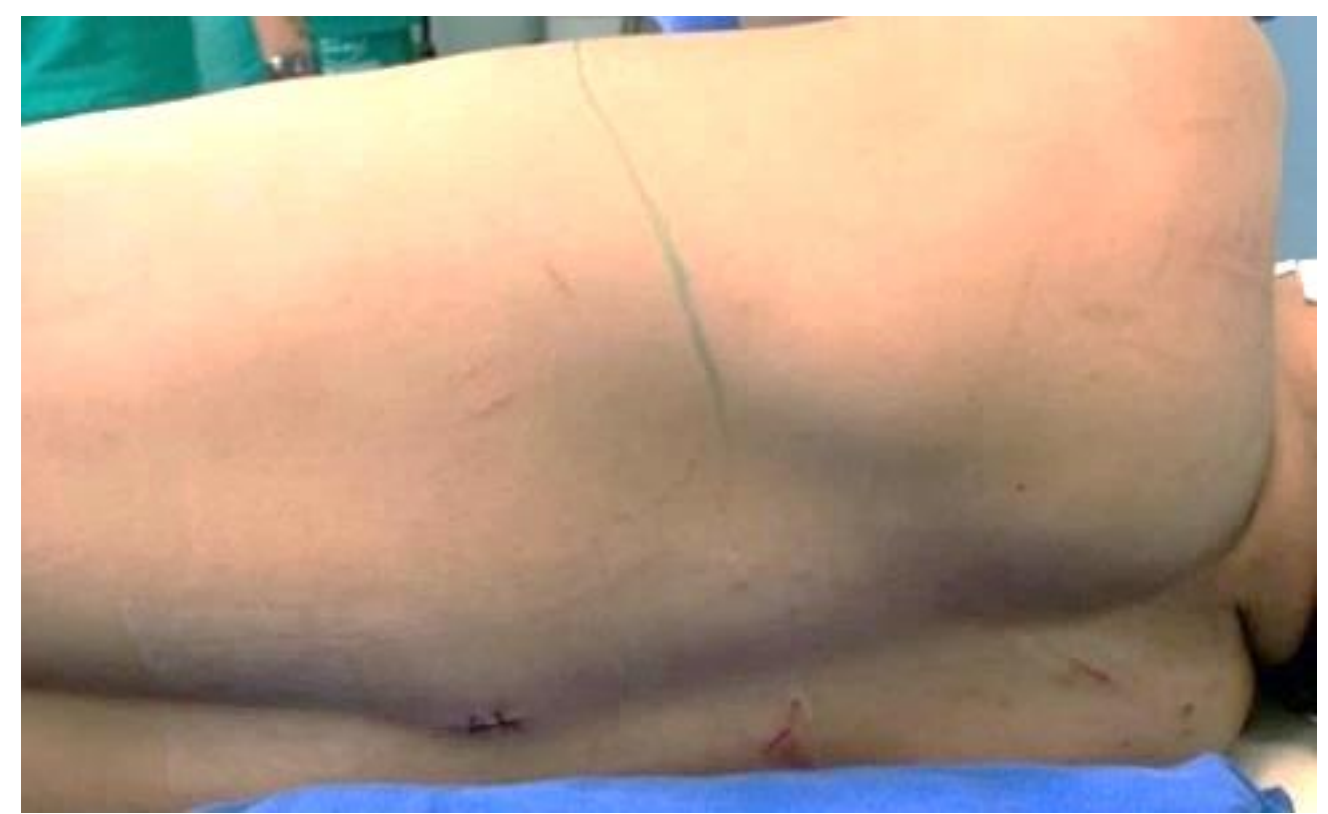

Fonte: Dias MAF, et al., 2020.

Na radiografia de tórax, em incidência ântero-posterior (AP), realizada no primeiro atendimento, havia a imagem do CEP metálico inserido na porção inferior do hemitórax esquerdo, compatível com pequena lâmina de faca, sugerindo, ainda, sua relação suspeita, porém não fidedigna, com o ápice da silhueta cardíaca e com a cúpula diafragmática esquerda (Figura 2).

O espaço intercostal (EIC) lesado não pôde ser identificado claramente nesta imagem. Portanto, diante do quadro clínico estável e para melhor definição diagnóstica das possíveis LTA, foi considerada a TC de tórax e abdome pela equipe de cirurgia geral. 
Figura 2 - Radiografia de tórax AP mostrando o CEP metálico (lâmina de faca) no hemitórax esquerdo.

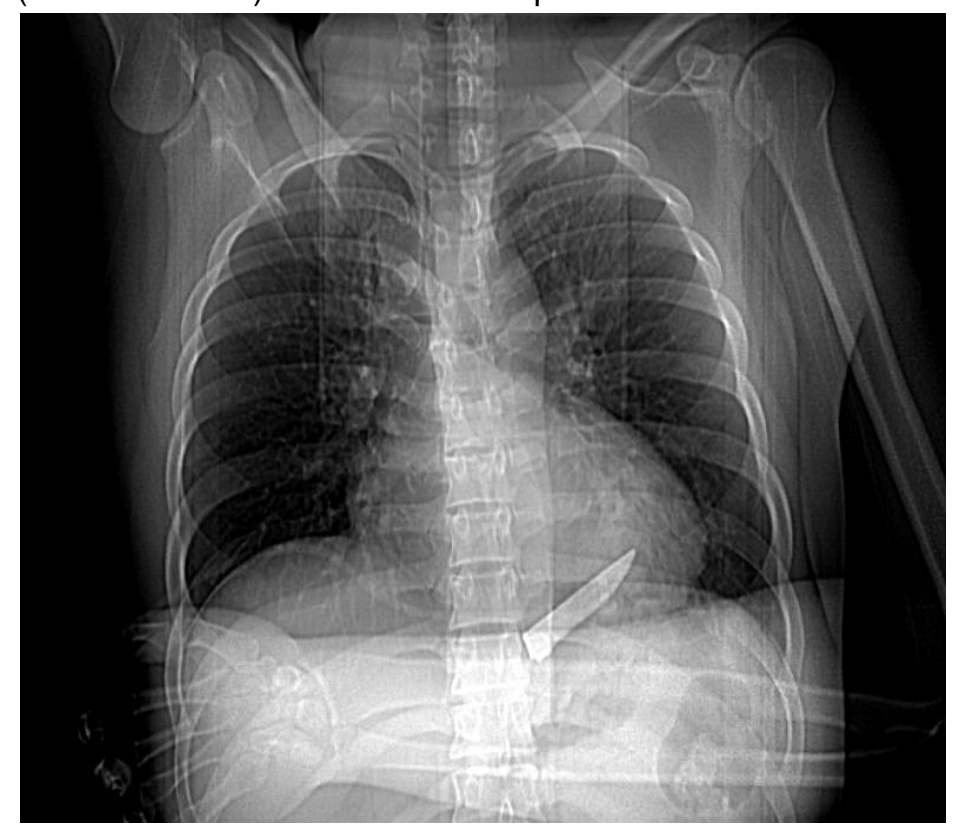

Fonte: Dias MAF, et al., 2020.

O paciente foi submetido à realização da TC, no hospital da capital, sendo os seus achados compatíveis com lesão póstero-basal do lobo pulmonar inferior esquerdo, associada à atelectasia do parênquima pulmonar adjacente a esta lesão e presença de pequeno hemotórax esquerdo, além da visualização da extremidade do CEP metálico permeando a lesão pulmonar, sem evidências da violação dos grandes vasos, esôfago, coluna vertebral, pericárdio, diafragma e cavidade abdominal (Figura 3).

Figura 3 - TC de tórax mostrando a lesão pulmonar esquerda associada ao CEP metálico e hemotórax.
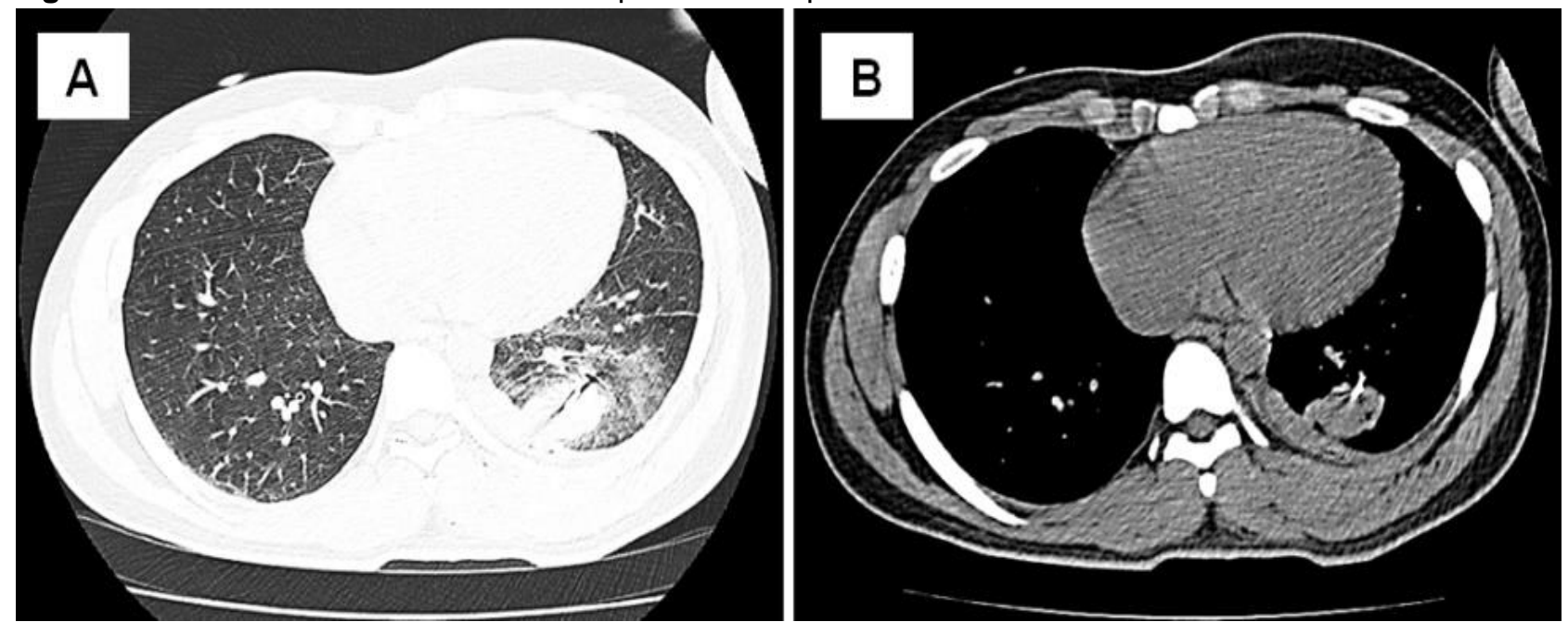

Legenda: $(A)$ : TC de tórax em janela pulmonar; $(B)$ : TC de tórax em janela mediastinal.

Fonte: Dias MAF, et al., 2020.

Foi possível compilar as imagens da TC de tórax por reconstrução em três dimensões (3D), a partir da subtração das partes moles, permitindo a identificação do arcabouço ósseo e a localização exata da posição do CEP: transfixando obliquamente a porção inferior da parede posterior do hemitórax esquerdo, ao nível do 9 EIC esquerdo, com progressão transversalmente lateral (Figura 4). Instituída a cobertura antibiótica, foi indicada a toracotomia exploradora de urgência para extração do CEP e correção das LTA. 
Figura 4 - TC de tórax por reconstrução em 3D mostrando o CEP transfixando o 9ำ EIC esquerdo.

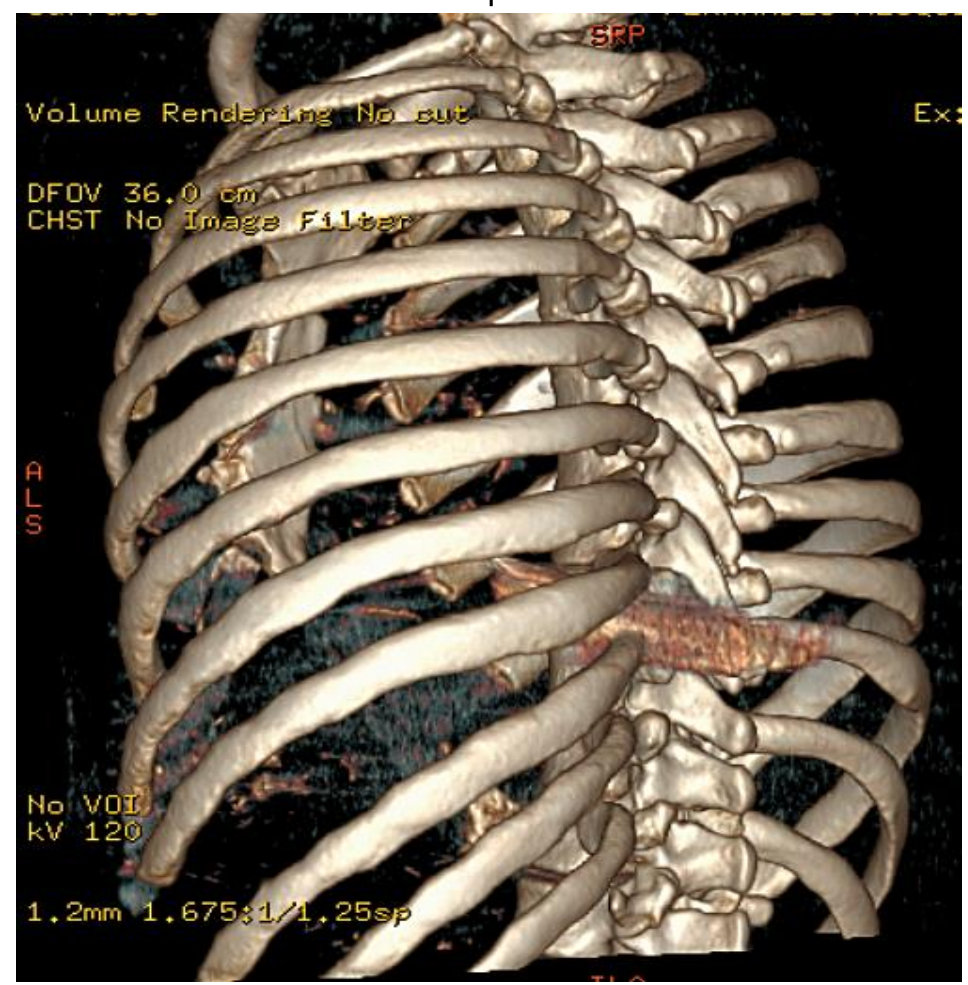

Fonte: Dias MAF, et al., 2020.

No inventário da cavidade, citamos: hemotórax esquerdo pouco volumoso; lesões da porção ínferoposterior do lobo pulmonar inferior esquerdo, do paquete neurovascular subcostal da $9^{\text {a }}$ costela esquerda e da musculatura do 9 EIC esquerdo; extremidade do CEP na porção inferior da parede posterior do hemitórax esquerdo (Figura 5A); cúpula frênica esquerda e pericárdio estavam íntegros.

Figura 5 - CEP metálico extraído e catalogado para destino às autoridades.
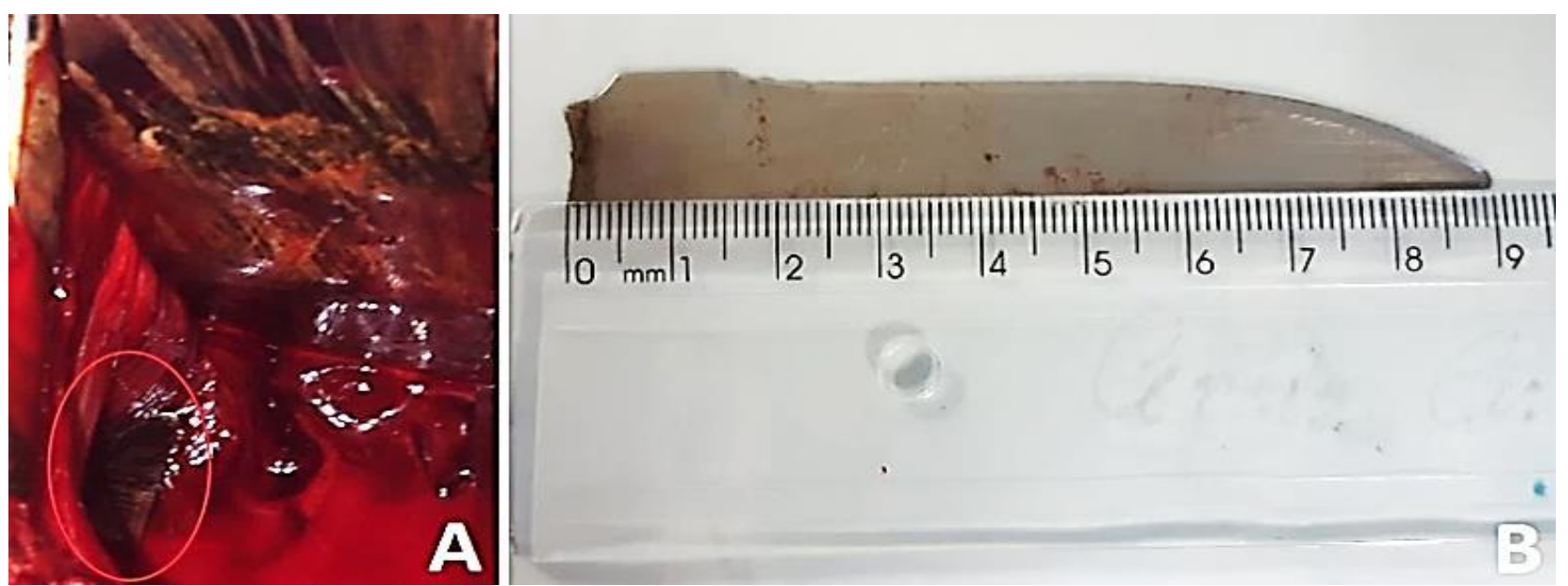

Legenda: (A): Extremidade na cavidade pleural em destaque; (B): Lâmina de $9 \mathrm{~cm}$.

Fonte: Dias MAF, et al., 2020.

No ato cirúrgico, foi realizada a extração do CEP metálico por sua tração através do ferimento no dorso, com visão direta da saída de sua extremidade da cavidade pleural (Figura 5B). Obtido o controle vascular subcostal com sutura hemostática, foi procedida a pneumorrafia, confecção da DFT, retirada de coágulos e revisão da cavidade pleural esquerda. Após uma intervenção cirúrgica satisfatória, o paciente foi conduzido 
para a sala de recuperação pós-anestésica, onde permaneceu sem intercorrências, sendo transferido para a enfermaria cirúrgica masculina.

No pós-operatório recente, evoluiu sem complicações pulmonares ou em feridas operatórias, com a retirada da DFT no 3o dia de pós-operatório (DPO). Alcançou melhora satisfatória precoce e recebeu alta hospitalar no $7^{\circ}$ DPO, sendo encaminhado para seguimento ambulatorial com a especialidade da cirurgia torácica. Atualmente, no $8^{\circ}$ mês de pós-operatório, refere mínima limitação álgica em suas atividades do cotidiano, informando retorno à prática de atividade física sem queixas respiratórias limitantes.

\section{DISCUSSÃO}

$\mathrm{Na}$ epidemiologia do ferimento por arma branca no tórax, são afetados, principalmente, homens jovens, nas três primeiras décadas de vida, com idade média de 21 anos. As agressões são as principais causas desse trauma e são significativos os casos em que há múltiplas lesões. Também é frequente a associação com o uso de álcool e drogas (PALLETT JR, et al., 2014; JOHANNESDOTTIR U, et al., 2019). O perfil do paciente em questão corrobora esta análise: adulto jovem, masculino, relatando agressão física próxima do seu domicílio e ferimentos múltiplos no dorso (Figura 1), informando consumo de álcool pelos presentes.

Nas últimas quatro décadas, em estudo chileno, houve um aumento na proporção das hospitalizações dos traumas torácicos por agressão e acidentes domésticos, bem como uma diminuição daqueles por acidentes de trânsito ou ocupacionais. Houve um predomínio do tipo penetrante e, consequentemente, um aumento do percentual das hospitalizações de lesões por armas brancas e armas de fogo, além de uma diminuição na proporção daqueles por elementos contundentes ou veículos automotores (LAGOS RG, et al., 2018). Essas informações demonstram plena analogia epidemiológica com as características aqui descritas.

Segundo um artigo islandês, nos países mais frios, as agressões são principalmente domésticas e, nos países mais quentes, ocorrem principalmente ao ar livre, como em locais públicos, pois o clima favorece maior exposição a ambientes externos (JOHANNESDOTTIR U, et al., 2019).

De fato, o estopim deste cenário se deu numa localidade de clima equatorial, caracteristicamente, quente e úmida, no centro da Floresta Amazônica, em local público, na área rural de um município pertencente à região metropolitana da capital de um estado amazônico.

As perfurações do tórax, mesmo quando a ferida externa aparenta ser inócua, são intimamente associadas ao aumento da mortalidade, que varia conforme a natureza das lesões decorrentes delas. Isso ocorre devido ao alto risco de LTA em estruturas intratorácicas, como coração, grandes vasos, pulmões, traqueia, árvore brônquica, esôfago, medula espinal, além da possibilidade de pneumotórax, hemotórax, hemopericárdio e infecções secundárias (FULLUM TM, et al., 1990; ZEBELE C, et al., 2011).

De acordo com o presente caso, demonstramos que um pequeno ferimento no dorso do hemitórax esquerdo, com discreto hematoma local e sutura realizada no atendimento inicial por alternativa hemostática (Figura 1), associado à presença de um CEP oculto, que foi diretamente responsável pela lesão neurovascular e muscular intercostal, lesão do parênquima pulmonar e hemotórax, ambos à esquerda (Figura 3). Porém, pela peculiaridade deste ferimento perfurante, as LTA não evoluíram precocemente para um desfecho plenamente negativo, havendo tempo hábil para o tratamento adequado do paciente. A retenção do CEP, mesmo que rara, também pode ocorrer. Essa situação pode passar despercebida, mesmo que não haja negligência. Nesses casos, além das complicações típicas das perfurações, também pode haver colonização bacteriana, resistência aos antimicrobianos e migração do fragmento retido, internamente (APILIOGULLARI B, et al., 2014). Além disso, a DFT associada ao trauma também tem uma significativa morbidade, sendo a presença do hemotórax um fator de risco significativo para o surgimento de complicações infecciosas (DíAS RI \& ANDRADE-ALEGRE R, 2013).

Nesse relato, o paciente apresentava a retenção do CEP no tórax, há pelo menos 6 horas, percebido apenas pelos métodos de imagem (Figuras 2,3 e 4). E, pela sabida contaminação bacteriana, foi iniciada a antibioticoterapia à admissão, sendo estendida ao pós-operatório com o objetivo de controlar, precocemente, a possível infecção da área afetada. Isso contribuiu para uma evolução sem infecção da cavidade pleural no 
seguimento pós-operatório. Em contraponto, o uso de antibióticos de maneira profilática na DFT tem sido um tema de amplo debate e pouco consenso (DÍAS RI \& ANDRADE-ALEGRE R, 2013).

Nas histórias de trauma e violência somadas ao exame físico com evidências de perfurações, a investigação diagnóstica é imprescindível para o sucesso do tratamento. Para tanto, os exames de imagem são importantes na identificação das possíveis LTA e na observação dos CEP, principalmente, as TC. A disponibilidade das TC nas urgências tem influência sobre um melhor prognóstico. Além disso, o estado do paciente também influencia o tempo de investigação diagnóstica. Estima-se um tempo médio de 44 minutos para a realização das TC nas urgências (APILIOGULLARI B, et al., 2014; NUMMELA MT, et al., 2019).

As LTA são caracterizadas nas TC pela observação de ar, sangue, osso ou fragmentos metálicos ao longo do curso dos projéteis e facadas. Em geral, os projéteis determinam lesões mais extensas, sendo que a TC tem grande capacidade de delinear o trajeto, inclusive em relação ao risco de lesões mediastinais. É fundamental a análise das TC nas janelas pulmonar, mediastinal e óssea, para melhor caracterização das injúrias associadas (MELO ASA, et al., 2017), principalmente nos pacientes estáveis, como demonstrado neste texto, contribuindo para a maior segurança cirúrgica do paciente (Figuras 3 e 4).

Dessa forma, diante da sua estabilidade clínica, o paciente foi submetido, incialmente, ao método disponível na sua localidade, uma radiografia AP (Figura 2), que apenas mostrava a presença do CEP no tórax, subsidiando sua transferência para avaliação no serviço de referência da capital. Após ser recebido e avaliado no hospital de urgências, mantendo estabilidade clínica, seguiu para a realização da TC (Figura 3) com reconstrução em 3D (Figura 4), após 30 minutos da admissão, sendo este método de fundamental valia não só para evidenciar com precisão a posição do CEP, mas também para definir as possíveis LTA.

O tratamento cirúrgico é indicado quando há lesão de estruturas intratorácicas, necessidade de remoção do CEP e seus contaminantes. Deve-se evitar a exploração da lesão e a manipulação ou remoção do CEP antes da conclusão diagnóstica e da estabilidade ventilatória do paciente (ILHAN M, et al., 2016). Neste sentido, pelo quadro clínico estável, não houve necessidade de medidas iniciais enérgicas e a toracotomia exploradora foi realizada após obtenção de uma história clínica consistente e exame físico fidedigno, aliados à pesquisa tomográfica, providenciais para o sucesso da intervenção cirúrgica e recuperação do paciente.

O manejo do trauma torácico progrediu intensamente nas últimas duas décadas, principalmente devido ao desenvolvimento dos auxílios diagnósticos, como a TC, radiografia digital, ultrassonografia e ressonância magnética. Os avanços nos cuidados intensivos, toracotomia de emergência, melhor controle da dor, fisioterapia respiratória e o apoio antimicrobiano também influenciaram (AGUIRRE SPO, et al., 2014). Todos esses elementos contribuíram para o desfecho satisfatório do quadro exposto, porém, mudanças sutis na cinemática deste trauma teriam ocasionado um desfecho potencialmente negativo, precocemente.

Por fim, fica evidente que as armas brancas têm elevada significância epidemiológica e seus ferimentos no tórax não devem ser julgados pela aparência da ferida externa, havendo extrema necessidade do rápido reconhecimento das possíveis LTA e da fisiopatologia envolvida. Há, ainda, a necessidade de intervenções que vão além da esfera da saúde, sendo a reeducação dos indivíduos um fator a ser considerado para evitar conflitos que culminem em agressões (PEREIRA ISM, et al., 2018). Dessa forma, a melhor construção do indivíduo, pautada na oferta digna da Educação e de demais serviços básicos ao cidadão, seria uma nítida aliada na prevenção da origem deste agravo à saúde pública, que, num cenário abrangente, toma forma de epidemia, em virtude dos seus números alarmantes em todo o mundo.

\section{REFERÊNCIAS}

1. AGUIRRE SPO, et al. Trauma torácico en la provincia de Cienfuegos - Estudio de tres años. MediSur Revista Electronica, 2014;12(1):77-84.

2. APILIOGULLARI B, et al. Retained foreign body after chest stab wound. Journal of Royal Army Medical Corps / BMJ Case Report, 2014;2014(1):1-3.

3. DA SILVA LAP, et al. Análise retrospectiva da prevalência e do perfil epidemiológico dos pacientes vítimas de trauma em um hospital secundário. Revista de Medicina da USP, 2017;96(4):246-54.

4. DÍAS RI e ANDRADE-ALEGRE R. Factores de riesgo para el desarrollo de complicaciones en las toracostomías cerradas por trauma. Panamerican Journal of Trauma, Critical Care and Emegency Surgery, 2013;2(2):69-73. 
5. FULLUM TM, et al. Stab wounds to the chest: a retrospective review of 100 consecutive cases. Journal of the National Medical Association, 1990;82(2):109-12.

6. ILHAN M, et al. A penetrating dorsal thoracic injury that is lucky from every aspect: A case report. International Journal of Surgery Case Reports, 2016;23(1):82-4.

7. JOHANNESDOTTIR U, et al. Penetrating stab injuries in Iceland: a whole-nation study on incidence and out-come in patients hospitalized for penetrating stab injuries. Scandinavian Journal of Trauma, Resuscitation and Emergency Medicine, 2019;27(7):1-6.

8. LAGOS RG, et al. Traumatismo torácico: caracterización de hospitalizaciones durante tres décadas. Revista Médica de Chile, 2018;146(2):196-205.

9. LAISAAR T. Unusual case of self-inflicted thoracic knife wounds with five knives embedded in the left thoracic cavity. European Journal of Cardio-Thoracic Surgery, 2005;28(4):653-4.

10. MELO ASA, et al. Aspectos tomográficos do trauma torácico aberto: lesões por projéteis de arma de fogo e armas brancas. Radiologia Brasileira - Colégio Brasileiro de Radiologia e Diagnóstico por Imagem, 2017;50(6):372-7.

11. NUMMELA MT, et al. Imaging of penetrating thoracic trauma in a large Nordic trauma center. Acta Radiologica Open, 2019;8(12):1-10.

12. PALLETT JR, et al. A cross-sectional study of knife injuries at a London major trauma centre. Annals of The Royal College of Surgeons of England, 2014;96(1):23-6.

13. PEREIRA ISM, et al. Trauma torácico por arma branca: complicações clínicas. Revista Acadêmica Ulbra Cachoeira do Sul, 2018;5(2).

14. ZANETTE GZ, et. al. Perfil epidemiológico do trauma torácico em um hospital referência da Foz do Rio Itajaí. Revista do Colégio Brasileiro de Cirurgiões, 2019;46(2):1-8.

15. ZEBELE C, et al. An unusual case of left chest stab wound. Asian Cardiovascular \& Thoracic Annals, 2011;19(5):34951. 